\title{
Linking Changes in Perceived Academic Control to University Dropout and University Grades: A Longitudinal Approach
}

\author{
Lisa Respondek and Tina Seufert \\ Ulm University
}

\author{
Jeremy M. Hamm \\ Concordia University
}

\author{
Ulrike E. Nett \\ Augsburg University
}

\begin{abstract}
Although research shows higher levels of perceived academic control are associated with academic adjustment in the first year of university, little is known about how changes in perceived control over multiple years relate to longitudinal university dropout and grades. Thus, our 3-year study $(N=1,007)$ examined whether changes in perceived control predicted university dropout and whether this relationship was mediated by university grade point average (GPA). Latent change score models showed that although first-year perceived control declined on average, there were high levels of variability between students, so that perceptions of control increased for some students. Discrete time survival analysis models showed that such positive changes in perceived control were associated with reduced dropout rates. Increases in perceived control also predicted higher subsequent university grades. Finally, we confirmed that the relationship between perceived control and dropout was mediated by university grades. Findings advance the literature in highlighting longitudinal linkages between perceived academic control and university grades and their influence on subsequent dropout. Implications for instructors and institutions to support adequate control perceptions, especially in the first academic year, are discussed.
\end{abstract}

\section{Educational Impact and Implications Statement}

The present study focuses on students' control beliefs over their academic outcomes and its relevance for university dropout and grades. Results suggest an overall decline of students' control beliefs within a 3-year degree program, and this decline was associated with a higher risk of university dropout and poorer university grades. These findings highlight the importance of developing evidence-based methods to support students' control beliefs.

Keywords: perceived academic control, university dropout, university grades (GPA), latent change score model, discrete time survival analysis

Supplemental materials: http://dx.doi.org/10.1037/edu0000388.supp

Students transitioning from high school to university face a variety of new and highly demanding challenges, among them increased autonomy, unfamiliar learning environments, increased pressures to excel, more frequent failure experiences, and greater responsibility for their educational outcomes (Credé \& Niehorster, 2012; Perry, 2003). These transition-related challenges have the
This article was published Online First July 22, 2019.

(1) Lisa Respondek and Tina Seufert, Department of Learning and Instruction, Institute of Psychology and Education, Ulm University; Jeremy M. Hamm, Department of Psychology, Concordia University; Ulrike E. Nett, Empirical Educational Research, Faculty of Philosophy and Social Sciences, Augsburg University.

We thank all participants for their support as well as our student assistants, who were involved in the data collection. The 1,007 students who participated in the present 3 year longitudinal study were, in part, the same sample as identified in the cross-sectional study of Respondek et al. (2017). To be more precise, the sample of Respondek et al. (2017) is a cross-sectional assessment. However, Respondek et al. (2017) also included students who did not provide consent to release their grade point averages. We note that in this previous cross-sectional study, dropout intention was the focus of the research questions rather than actual dropout, as in the present study. Perceived academic control and university grades were predictors in both studies. This work was funded by the "Quality Pact for Teaching," a joint program of the Federal Ministry of Education and Research (grant 001PL11011 and 01PL16011). Finally, we would like to further note that this work is part of the dissertation project of the first author, Lisa Respondek.

Correspondence concerning this article should be addressed to Lisa Respondek, Department of Learning and Instruction, Institute of Psychology and Education, Ulm University, Albert-Einstein-Allee 47, D-89081 Ulm, or to Ulrike E. Nett, Empirical Educational Research, Augsburg University, Universitätsstr. 10, D-86135 Augsburg. E-mail: lisa.respondek@uni-ulm.de or ulrike.nett@phil.uni-augsburg.de 
potential to precipitate negative changes in students' perceptions of control (Perry, 2003). Reductions in academic control have been shown to undermine motivation and achievement striving in otherwise committed students and can lead to negative consequences such as university dropout or poor grades (e.g., Perry, Hladkyj, Pekrun, Clifton, \& Chipperfield, 2005; Perry, Hladkyj, Pekrun, \& Pelletier, 2001). However, not all students experience declines in their perceived control. Some may even experience increased perceived control if initial successes give rise to positive reciprocal associations between perceived control and grades. However, little is known about the longitudinal interrelationships between perceived academic control, university dropout, and university grades that unfold over multiple years of students' academic programs. The present study examined how perceived academic control changed over an entire undergraduate program and how such changes predicted university dropout and university grades.

\section{Perceived Academic Control (PAC) of University Students}

Perceived academic control (PAC) refers to beliefs about personal influence over one's academic achievement outcomes (Perry, 1991). This individual perception is distinguished from students' 'veridical' influence over their outcomes, for example because of having high levels of autonomy or flexibility (Heckhausen \& Schulz, 1995). Specifically, Heckhausen and Schulz (1995) argued that PAC can be distinguished by its degree of veridicality, meaning to what extent it is based on well-grounded elements of the university setting and causality of action and outcome. PAC is the domain-specific component of perceived control, which has significant implications for motivation and achievement (for an overview see Skinner, 1996).

Theoretically, PAC is connected to the attributions students make for their achievement outcomes (Weiner, 1985, 2018). According to Weiner (2018), attributions can be classified based on three causal dimensions that involve locus of causality (internal vs. external), stability (stable vs. unstable), and controllability (controllable vs. uncontrollable). Students' attributions have been posited to impact their PAC (Perry, Hall, \& Ruthig, 2005). For example, if students attribute a failure to internal, stable, and uncontrollable causes (e.g., low ability), they will perceive lower levels of PAC. In contrast, if students explain the same failure as because of due to internal, unstable, and controllable causes (e.g., low effort), they will perceive higher levels of PAC (Hamm, Perry, Chipperfield, Murayama, \& Weiner, 2017). Increasing evidence shows PAC is positively associated with the motivation to learn, use of effective study strategies, adjustment to university, mastery orientation, and so forth (Cassidy \& Eachus, 2000; Hall, Perry, Ruthig, Hladkyj, \& Chipperfield, 2006; Perry et al., 2001).

PAC has been shown to be particularly important for freshman students who must adjust to the unfamiliar learning circumstances of university and to overcome, for example, increased pressure to excel, frequent failures, or unfamiliar learning tasks (Perry, 1991; Perry, Hall, et al., 2005). This transition to university has the capacity to undermine students' PAC, which can lead to negative consequences as mentioned earlier. To prevent such outcomes, prior research, therefore, mostly focused on the first-year experience.
PAC is assumed to be a relatively stable psychological disposition (Perry, Hall, et al., 2005; Perry et al., 2001). For instance, Ruthig, Hanson, and Marino (2009) showed PAC to be fairly stable within the first year of university. Other research showed PAC exhibited change only when measured over long durations compared with daily measures, pointing to a slow changing process, with overall levels slightly decreasing with time (Stupnisky, Perry, Hall, \& Guay, 2012). Similarly, Niculescu, Tempelaar, Dailey-Hebert, Segers, and Gijselaers (2016) showed a minor negative trend within a freshman introductory course, with high individual variability concerning those changes. First-year university students typically report increased levels of PAC after successes and decreased levels after failure experiences (Hall, 2008). However, these studies focused solely on the development of PAC within the first academic year. Initial cross-sectional research by Respondek, Seufert, Stupnisky, and Nett (2017) started to fill this gap with a comparison of the level of first and second year undergraduate students' PAC. The results suggested a decline, as PAC levels for second year students were lower (Respondek et al., 2017). Yet, little is known about how PAC changes throughout entire undergraduate programs and the implications of such changes for university dropout and university grades (see lower rectangle in Figure 1, Objective 1).

\section{PAC and University Dropout}

Academic retention (persisting vs. dropping out) is a key element of university success (Robbins, Lauver, Le, Davis, Langley, \& Carlstrom, 2004; Robbins, Oh, Le, \& Button, 2009). University dropout has negative societal consequences, such as fewer qualified employees in the workforce (e.g., Heublein \& Wolter, 2011), as well as personal consequences, such as reduced personal income, lower perceived happiness, higher reported depression, and increased stress (Faas, Benson, Kaestle, \& Savla, 2018). Rising dropout rates point to a strong need for action: Among the 23 OECD countries, about a third of students drop out of university (OECD, 2012). In Germany, university dropout rates during the previous 13 years have increased from 25 to $33 \%$ (Heublein, 2014). Despite high dropout rates during the first year, some students still drop out in subsequent years (Mabel \& Britton, 2018). A recent German study showed that $47 \%$ of dropouts occurred in the first academic year, $29 \%$ in the second year, $12 \%$ in the third year, and $12 \%$ after the third year (Heublein et al., 2017).

Therefore, it is necessary to identify central factors that affect dropout over entire undergraduate programs. In the psychological model of college student retention (Bean \& Eaton, 2001), it is assumed that PAC is one key psychological process within the institutional environment. Bean and Eaton (2001) argue that high PAC is linked to increased academic and social motivation in university achievement settings. This, in turn leads to academic and social integration, which leads to institutional fit and, therefore, reduces students' dropout.

Supporting theoretical assumptions concerning the importance of PAC for retention, there is also empirical evidence suggesting that PAC is relevant for university dropout. Preliminary research in this area found that first-year PAC was related to reduced course withdrawal (Hall et al., 2006; Ruthig, Haynes, Perry, \& Chipperfield, 2007) and to university dropout (Perry, Hladkyj, et al., 


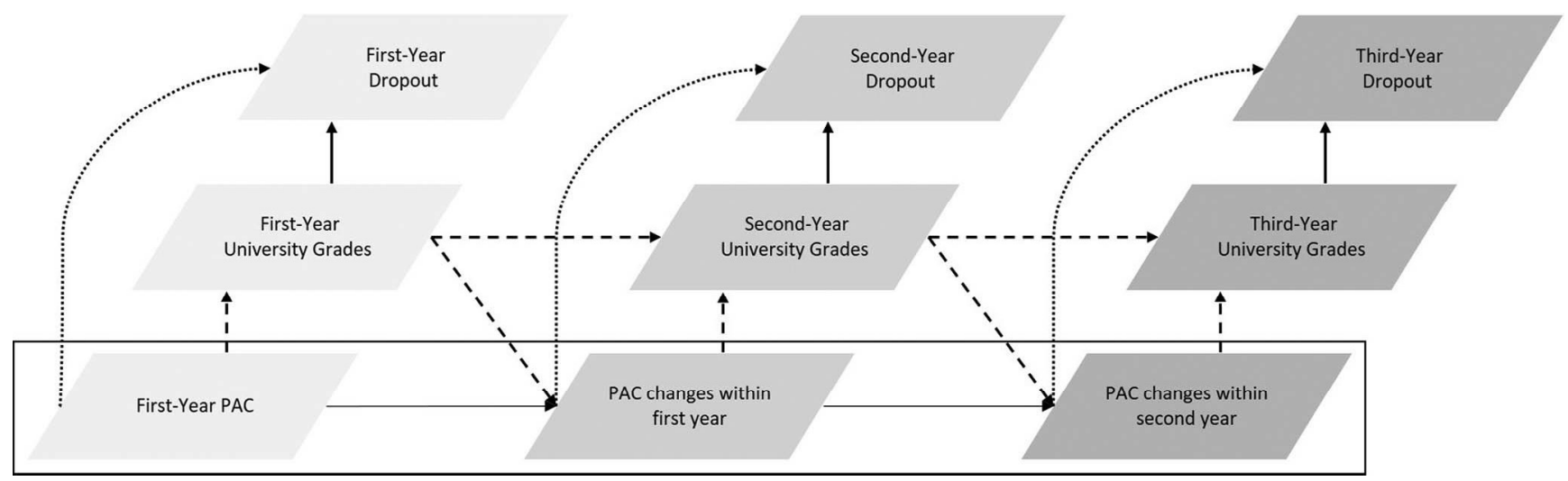

Figure 1. Overview of the study purpose and research objectives that focus on change in perceived academic control (PAC) over time and its impact on university dropout, mediated by university grades. The lower rectangle indicates the change focus (Objective 1), the dotted lines indicates the dropout focus (Objective 2a), the dashed lines indicate the grade focus (Objective 2b), and the full model indicates the mediation focus (Objective 3).

2005). However, prior research focused mostly on the first academic year (Willcoxson, Cotter, \& Joy, 2011) and did not account for the different times of dropout, such as early versus late (DesJardins, Ahlburg, \& McCall, 1999; Mabel \& Britton, 2018), despite the fact that PAC seems to be differentially related to dropout intention across academic years (Respondek et al., 2017). As discussed by Alarcon and Edwards (2013) it is necessary to use multiple measurements and longitudinal data to understand the relevance of motivational variables such as PAC for dropout. Thus, our study addressed how PAC influenced dropout over an entire undergraduate program of study, while also testing whether its influence differed for early or late dropout (see dotted lines in Figure 1, Objective 2a).

\section{PAC and University Grades}

University grades are the second key element of university success (Robbins et al., 2004, 2009). They are strongly predicted by high school grades (e.g., Geiser \& Santelices, 2007) and reflect a combination of students' academic skills and abilities, work habits, and content knowledge (Hamm, Perry, Chipperfield, Parker, \& Heckhausen, 2019). Further, early postsecondary grades strongly predict subsequent achievement outcomes (e.g., Richardson, Abraham, \& Bond, 2012; Schneider \& Preckel, 2017).

Prior research revealed the positive impact of first-year PAC on students' grades within the critical first academic year (e.g., Daniels et al., 2014; Hall et al., 2006). For instance, PAC at the beginning of an introductory course related positively to the test performance throughout the course and to final course grades (Perry et al., 2001). First-year PAC seems to have long-term enhancing effects on university grades within the first academic year, as the impact of high PAC levels on course grades was greater for 6-months compared with 2-week periods (Stupnisky et al., 2012). These findings are consistent with other research that shows the long-term positive influence of first-year PAC on students' grades over a 3-year period, which remained significant even when high school grades were controlled (Perry et al., 2001). Besides a high level of PAC, Stupnisky et al. (2012) found that high stability in first-year PAC was also important for freshman grades. Finally, a meta-analysis about university grades underscored the relevance of PAC, as it showed an overall moderate positive relationship to university grades (Richardson et al., 2012).

An important issue that has yet to be systematically addressed in the literature concerns positive reciprocal associations that may emerge between PAC and university grades over time. High school grades are positively associated with PAC at the beginning of first-year at university, which is in turn positively associated with subsequent university grades (Hall et al., 2006; Perry, Hladkyj, et al., 2005; Perry et al., 2001). This implies that initial grades may foster positive shifts in PAC, which may lead to better university grades, which may in turn lead to increased PAC and so on. The present study sought to advance this work by analyzing whether positive reciprocal associations emerged throughout an entire undergraduate program of study. We focus on the influence of university grades on changes in PAC and the influence of those changes in control on subsequent university grades (see dashed line in Figure 1, Objective 2b).

\section{Interrelationships Between PAC, University Dropout, and University Grades}

Both key elements of university success are related, as university grade point average (GPA) predicts dropout (e.g., Robbins et al., 2004, 2009), especially in the first year (Allen, Robbins, Casillas, \& Oh, 2008; Pascarella \& Terenzini, 2005). High school grades also predict dropout (e.g., Stewart, Lim, \& Kim, 2015), even in later years (Mabel \& Britton, 2018). Approximately a third of the variance in dropout can be explained by high school and university grades (Voelkle \& Sander, 2008).

Previous research suggests that first-year PAC is also associated with reduced university dropout (Perry, Hladkyj, et al., 2005; see section 'PAC and University Dropout'; cf. direct effect). However, its influence may be indirect since first-year PAC also predicts increased university grades (Perry et al., 2001; see section 'PAC and University Grades') and university grades predict university dropout (Voelkle \& Sander, 2008). These findings suggest that the relationship between PAC and university dropout may be mediated by university grades. This would be in line with theoretical prop- 
ositions forwarded by Bean and Eaton (2001) who proposed that intermediate outcomes (e.g., performance) mediate the effect of psychological processes (e.g., PAC) on student dropouts. However, empirical research has yet to systematically examine this proposition. Our study addressed the interrelationships between PAC, university dropout and university grades over students' entire undergraduate program of study (see Figure 1, Objective 3).

\section{Study Purpose and Research Objectives}

The present study sought to extend prior research by examining the role of PAC over an entire undergraduate program of study. Our focus was on its associations with university dropout and university GPA within and beyond the first academic year.

Our first objective was to analyze change in PAC over multiple years of an academic program. As stated above, research has yet to analyze PAC beyond the critical first academic year. We expected PAC to decrease significantly within the first academic year (cf. Respondek et al., 2017). When students first begin university, they may be unaware of how much control they actually have (veridical control) due to entering a novel and unfamiliar learning environment. This could result in overestimates of PAC in the first year that is subsequently recalibrated (lowered) to better match reality. After the first-year, PAC declines may be attenuated and PAC may even remain relatively stable in subsequent years, as students have adjusted to the new demands and are now aware of their actual levels of control (cf. Perry et al., 2001). Alternatively, PAC could increase in students who did not drop out and are experiencing success, which might enhance control perceptions (change focus, Figure 1).

Our second objective was to analyze how changes in PAC are relevant for university success over an entire academic program of study. We examined the interrelationships between changes in PAC, university dropout, and university grades (GPA). In a first step, we focused on PAC change and university dropout. Preliminary evidence suggests that PAC is associated with decreased probability of dropout (cf. Perry, Hladkyj, et al., 2005). The present study built on this research by testing whether the relationship between PAC and dropout differs during a 3-year undergraduate program, with a focus on the impact of changes in PAC. We expected positive changes (increases) in PAC to predict reduced odds of university dropout (dropout focus, Figure 1).

In a second step, we also examined relationships between PAC and GPA over multiple academic years, to extend prior research that focused on the first year only (e.g., Perry et al., 2001; Stupnisky et al., 2007). Therefore, this study focused on how changes in PAC influence and are influenced by GPA within all three undergraduate academic years, by simultaneously considering university dropout. We expected positive changes (increases) in PAC to positively predict GPA, which was in turn expected to predict increases in PAC as part of a positive reciprocal association that emerges over time (grade focus, Figure 1).

Our third objective was to test previously unexamined interrelationships between PAC, university dropout, and GPA. We expected GPA to mediate the association between PAC and university dropout. Specifically, we expected that positive changes in PAC would predict increased GPA, which would in turn predict reduced odds of university dropout (mediation focus, Figure 1). In summary, first, positive reciprocal associations were expected between GPA and PAC (grade focus) and, second, GPA was expected to mediate the impact of PAC on dropout (mediation focus).

\section{Method}

\section{Participants and Procedures}

The present study followed two cohorts of students over 3 years. Cohort A consisted of 387 students who first enrolled in Winter, 2013 and Cohort B consisted of 620 students who first enrolled in Winter, 2014. Altogether, 1007 undergraduate students participated in the study (see Table 1 for demographics). ${ }^{1}$ The students were enrolled in different disciplines offered by a German university $(20.9 \%$ psychology, $18.3 \%$ biology, $16.4 \%$ economics, $15.1 \%$ mathematics, $8.4 \%$ chemistry, $7.9 \%$ computer science, $6.8 \%$ physics, and $6.2 \%$ engineering). Participation was voluntary, all participants gave written informed consent in accordance with the Declaration of Helsinki, and participants had the chance to withdraw their consent at any point of the study.

This longitudinal study consisted of multiple measurements throughout entire 3-year bachelor programs, which are the most common undergraduate programs in Germany (see Figure 2). Questionnaires that assessed PAC were administered at the beginning of the first, second, and third academic year (in November). They were distributed to the students during an important lecture of each discipline. We were able to match the questionnaires over time via a participation code. However, missing data occurred as not all students took part in all three measurements. $^{2}$ Those missing data occurred in two ways:

\footnotetext{
${ }^{1}$ To merge the two cohorts into one sample, we compared them on several demographic measures and study variables. The $t$ test and $\chi^{2}$ test for categorical data showed that cohorts did not differ regarding age, sex, nationality, or overall PAC, but differed slightly on overall GPA $(t(878)=4.98, p<.001$, $d=0.30)$ and dropout $\left(\chi^{2}(1)=20.70, p<.001, O R_{\text {dropout }}=0.50\right)$. The results of the mean comparisons can be found in detail in the online supplemental material. We also note that, in two of eight disciplines, minor curriculum changes occurred between the cohorts. Therefore, in the following results, we cohort-centered GPA. An additional analysis of the final model (Figure 5) with cohort as a covariate (also in online supplemental material) yielded consistent results as those reported in the main analyses, despite the expected small impact of cohort on dropout.

${ }^{2}$ We compared students with full data, to those with missing data, and to those who dropped out regarding their self-reported PAC, GPAs, and demographic variables (sex, age, and nationality). Overall we found no significant mean differences concerning PAC, sex, age, and nationality. For the second measurement, we found that students who dropped out had poorer GPAs compared with students with missing data and full data. Further, students with full data had higher GPAs compared with students with missing data. For the third measurement, we found that students who dropped out had poorer GPAs compared with students with missing data and full data, but no difference was observed between students with full data and missing data for GPAs (for details see online supplemental material). Based on the relevance of dropout and GPAs for the missingness and to account for the partial MNAR mechanism (Enders, 2010), we recalculated the model considering dropout and GPA as auxiliary variables in our latent change score model of PAC (change focus). The results of the models with and without the auxiliary variables (dropout, GPAs) were largely consistent (see the online supplemental materials). Only changes in PAC in the second academic year (delta 23) varied from $M=-0.11, p=.030$ without auxiliary variables to $M=-0.16, p=.070$ with auxiliary variables. For this reason and because of its very small effect size, we do not interpret this parameter. As both variables (dropout and GPAs) are part of our final model (Figure 5), the MNAR mechanism becomes MAR for this model (Enders, 2010).
} 
Table 1

Demographics of Participants

\begin{tabular}{|c|c|c|c|c|c|c|c|}
\hline \multirow[b]{2}{*}{ Sample } & \multirow[b]{2}{*}{$n$} & \multirow[b]{2}{*}{ Sex } & \multirow[b]{2}{*}{ Language } & \multirow[b]{2}{*}{ Nationality } & \multicolumn{3}{|c|}{ Age } \\
\hline & & & & & $M_{\text {age }}$ & $S D_{\text {age }}$ & Range \\
\hline Cohort A & 387 & $49.1 \%$ female & $87.6 \%$ German & $93.8 \%$ German & 19.92 & 1.95 & $16-30$ \\
\hline Cohort B & 620 & $47.9 \%$ female & $83.1 \%$ German & $92.1 \%$ German & 20.18 & 3.34 & $17-52$ \\
\hline Total sample & 1,007 & $48.4 \%$ female & $84.8 \%$ German & $92.8 \%$ German & 20.08 & 2.88 & $16-52$ \\
\hline
\end{tabular}

Note. Cohort A enrolled Winter 2013, Cohort B enrolled Winter 2014; language indicates mother tongue, age measured in years at the beginning of their study.

either systematically via university dropout, which this study accounts for via discrete time survival analysis. Alternatively, it occurred unsystematically as some students were missing in those lectures where we conducted the survey. This could be because of various reasons such as not wishing to participate or absences because of illness, personal time constraints, premature completion of this study module, and so forth. Because of conducting our study during highly relevant lectures, attrition rates were acceptable and resulted in an overall attrition rate of $41.8 \%$, which is comparable with other longitudinal field studies in higher education (e.g., 49\%; Perry et al., 2001).

In addition to the survey, students consented to release their current enrolment status (dropout) and GPA by signing a data privacy statement and providing their participation code in combination with their matriculation number. We used this matriculation number to request students' enrollment status from institutional records at the end of the undergraduate study program of both cohorts (September 2017). We were able to record if and when students withdrew from their freshman major. Therefore, this study also includes late dropout data. Dropout contains no missing data (see Figure 2). Further, we used the matriculation number to obtain students' cumulative GPA from institutional records at the midpoint of the first, second, and third year (beginning of April; at this time the students received the first comprehensive performance feedbacks). Because of technical and formal issues in the institutional records, we could not access the current GPA for all students (up to $11.7 \%$ missing; Figure 2).

\section{Measures}

Perceived Academic Control (PAC). PAC was measured using the German translation of the Academic Control Scale (Perry, 1991; Perry et al., 2001; in its German version of Pekrun et al., 2004). Students rated six items on a 5-point Likert scale $(1=$ strongly disagree, $5=$ strongly agree $; N_{1}=990,{ }^{3} M_{1}=4.02$, $S D_{1}=0.52 ; N_{2}=462, M_{2}=3.84, S D_{2}=0.71 ; N_{3}=171, M_{3}=$ $3.70, S D_{3}=0.74$ ). An example item was, "I have a great deal of control over my academic performance" (see online supplemental materials for details). To obtain an interpretable and informative zero-point for the discrete time survival analysis model, PAC items from the first measurement occasion were mean centered. To create interpretable scores for the latent change score model, the PAC items from the second and third measurement occasion were centered by the same value as the respective item from the first measurement occasion. We confirmed the measurement model for PAC (see online supplemental materials for details): All McDon- alds Omega scores were higher than .70, supporting the internal reliability of our measure of PAC. The confirmatory factor analysis for PAC showed acceptable fit for each academic year. Sixteen of 18 standardized factor loadings for the latent PAC variable were higher than the acceptable cut-off of 0.50 (Hair, Black, Babin, \& Anderson, 2010). Nine of them were higher than the recommended ideal cut-off of 0.70 (Hair et al., 2010). Two standardized factor loadings were close to 0.50 but did not meet the cut-off criterion. Still they did meet the more liberal cut-off criterion of .40 (Stevens, 2009).

Dropout. Dropout was assessed using institutional records and reflected whether or not students remained enrolled in their freshman major (for an overview of common operationalizations see Bahr, 2009; for specific dropout types see Bernardo et al., 2017). In detail, we considered different perspectives in our dropout operationalization. The total observed dropout $(n=271)$ included the perspective of the faculty dean by students leaving this specific faculty (major transition, $n=52$ ), the perspective of the university by students leaving this specific university (university transition, $n=66$ ), and the perspective of the German government by students withdrawing from university (complete dropout, $n=153)$. Dropout was coded as a dichotomous variable $(0=$ did not drop, 1 = dropped out).

University grades. Consistent with prior research, university grades were operationalized as students' cumulative GPA, measured at the midpoint of each academic year. They were obtained from institutional records and contained students' average grades achieved in all completed courses up until that point. Additionally, we obtained participant high school GPAs via self-report $\left(N_{O}=\right.$ 991). Each GPA was cohort-centered $\left(M_{G P A O}=0, S D_{G P A O}=.58\right.$, $M_{G P A I}=0, S D_{G P A I}=.74 ; M_{G P A 2}=0, S D_{G P A 2}=.66 ; M_{G P A 3}=$ $\left.0, S D_{G P A 3}=.61\right)$. Further, because of the German grading system (originally from $1.0=$ excellent to $5.0=$ failed), we transformed each GPA by multiplying -1 so that higher grades reflect higher performance.

\section{Rationale for Analyses}

Regarding our first objective, we estimated a Latent Change Score model to assess change in PAC over time (change focus;

\footnotetext{
${ }^{3}$ At the first point of measurement, 17 of the 1,007 students participated in the questionnaire and gave their consent to release their current enrolment status and GPA by signing a data privacy statement, but did not provide data on their PAC.
} 


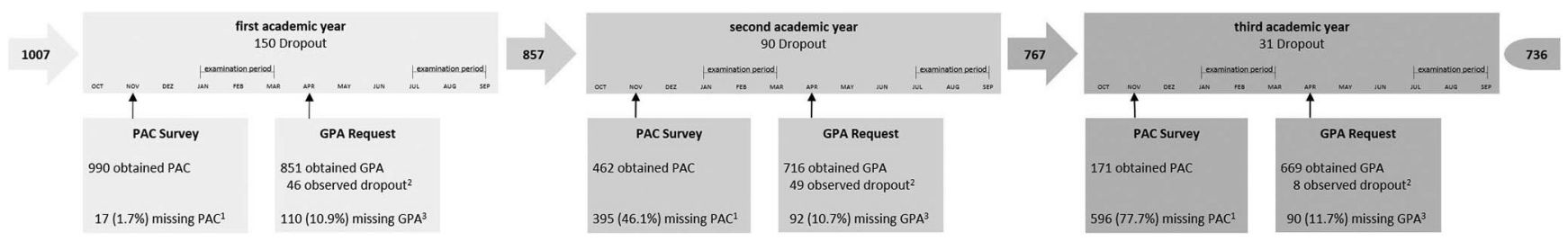

Figure 2. Overview of the obtained data for every measurement point over all three undergraduate academic years. Arrows indicate number of students starting each specific year. Perceived academic control (PAC) was obtained via self-report in November of each year (PAC Survey). Obtained PAC indicates number of completed PAC questionnaire at that specific point in time. ${ }^{1}$ Missing $P A C$ indicates missing because of nonvalid item response. University grades were requested from the office of institutional records in April of each year (GPA Request). Obtained GPA indicates number of successfully received GPAs. ${ }^{2}$ Observed dropout indicates students' dropout before GPA request. ${ }^{3}$ Missing GPA indicates missing because of technical issues and unsuccessfully obtained GPA. Percentage in parentheses indicates portion of missing on starting sample of each specific year (attrition rate).

Figure 3; also called true change model or latent difference model, cf. McArdle, 2001; Steyer, Eid, \& Schwenkmezger, 1997; Steyer, Partchev, \& Shanahan, 2000). Via this structural equation model, we took the measurement error into account and described the change between two measurement occasions as unobserved latent variables $(\Delta)$. Significant mean change $\left(\mu_{\Delta}\right)$ indicated reliable mean differences in PAC over all participants. Significant change variance $\left(\sigma_{\Delta}^{2}\right)$ indicated individual variability of these overall mean differences (McArdle, 2001). We estimated a Neighbor-Change model (Steyer et al., 2000), capturing the change of PAC within the first (eq. $\mathrm{PAC}_{\Delta 12}$ ) and the second academic year (eq. $\mathrm{PAC}_{\Delta 23}$ ). Further, factor loadings and intercepts were constrained to be equal across measurement (strong measurement invariance; cf. Steyer et al., 2000, see online supplemental materials for details). Autocorrelated error variables were accounted for via correlations between residual variances of the same indicators across time (e.g., Christ \& Schlüter, 2012; Geiser, 2011).

Regarding our second objective, we estimated a Discrete Time Survival Analysis model for dropout (DTSA; cf. Masyn, 2003, 2014; Muthén \& Masyn, 2005; Voelkle \& Sander, 2008). Generally, DTSA accounts for the timing of the event 'university dropout,' which is one of the main advantages over logistic regression (Voelkle \& Sander, 2008). The DTSA modeled whether and when students dropped out (cf. latent hazard function): The dropout probability or dropout risk is estimated by hazard rates $(\mathrm{h}(\mathrm{t})=$ $1 /(1+$ eThreshold $))$ for every undergraduate academic year.

In a first step, we examined whether latent changes in PAC predicted subsequent dropout (dropout focus, Figure 4; cf. McArdle, 2001). Thereby, the conditional dropout risk (i.e., under consideration of the study predictors) were indicated by odd ratios $\left(O R=\mathrm{e}^{\text {estimate }}\right)$ : It represents the ratio between the odds after a unit change in the predictor and the original odds. For instance, an $O R$ value of 0.60 for $\mathrm{PAC}_{\Delta 12}$ would indicate that each unit increase in the change of PAC within the first year was associated with a $60 \%$ reduction in odds of university dropout in the second year.

In a second step, we added GPA to the DTSA model, with high school GPA as a time-invariant predictor and university GPA in Years $1-3$ as a time-varying predictor (grade focus, Figure 5). Via this structural equation model we could test the hypothesized positive reciprocal longitudinal associations between PAC and GPA.
Regarding our third objective, we tested whether GPA mediated the influence of PAC on dropout by testing the significance of indirect effects for each undergraduate year (mediation focus, Figure 5; cf. Fairchild, Abara, Gottschall, Tein, \& Prinz, 2015). Note that temporal sequencing of the model was preserved as each variable in the longitudinal mediation model was measured at separate (nonoverlapping) time points (see Figure 2).

All analyses were conducted using Mplus 8 (Muthén \& Muthén, 1998-2017). Missing data were accounted for by using the full information maximum likelihood estimator (FIML) with $S E$ s that are robust to nonnormality and nonindependence of observations (MLR). We considered various fit indices based on $\mathrm{Hu}$ and Bentler (1999). Acceptable model fit was indicated through $\chi^{2}$, root mean square error of approximation (RMSEA $\leq 0.05)$, comparative fit index (CFI $\geq 0.95)$, and standardized root mean square residual (SRMR $\leq 0.08)$. The syntax was based on previous research (Fairchild et al., 2015; Gottschall, Fairchild, Masyn, \& Prinz, 2013; Muthén \& Muthén, 1998-2017) and is provided as online supplemental material.

\section{Results}

\section{Preliminary Results}

Table 2 provides correlations among all study variables. PAC showed relatively high stability, indicated by strong correlations over the three academic years. PAC only related meaningfully to dropout in the second academic year. The university GPA measures also exhibited strong, positive relations over time. The strong positive association between PAC and GPA seemed to increase over time. Finally, GPA showed a robust negative relationship with dropout.

\section{Change Focus}

To address our first research objective, we examined change in PAC over an entire program of study using a latent neighborchange model (see Figure 3). Results of models with strong measurement invariance and indicator-specific effects showed acceptable model fit $\left(\chi^{2}(134)=271.51, p<.001\right.$, RMSEA $=0.03$, $\mathrm{CFI}=0.94$, SRMR $=0.07)$. On average over all students, PAC 


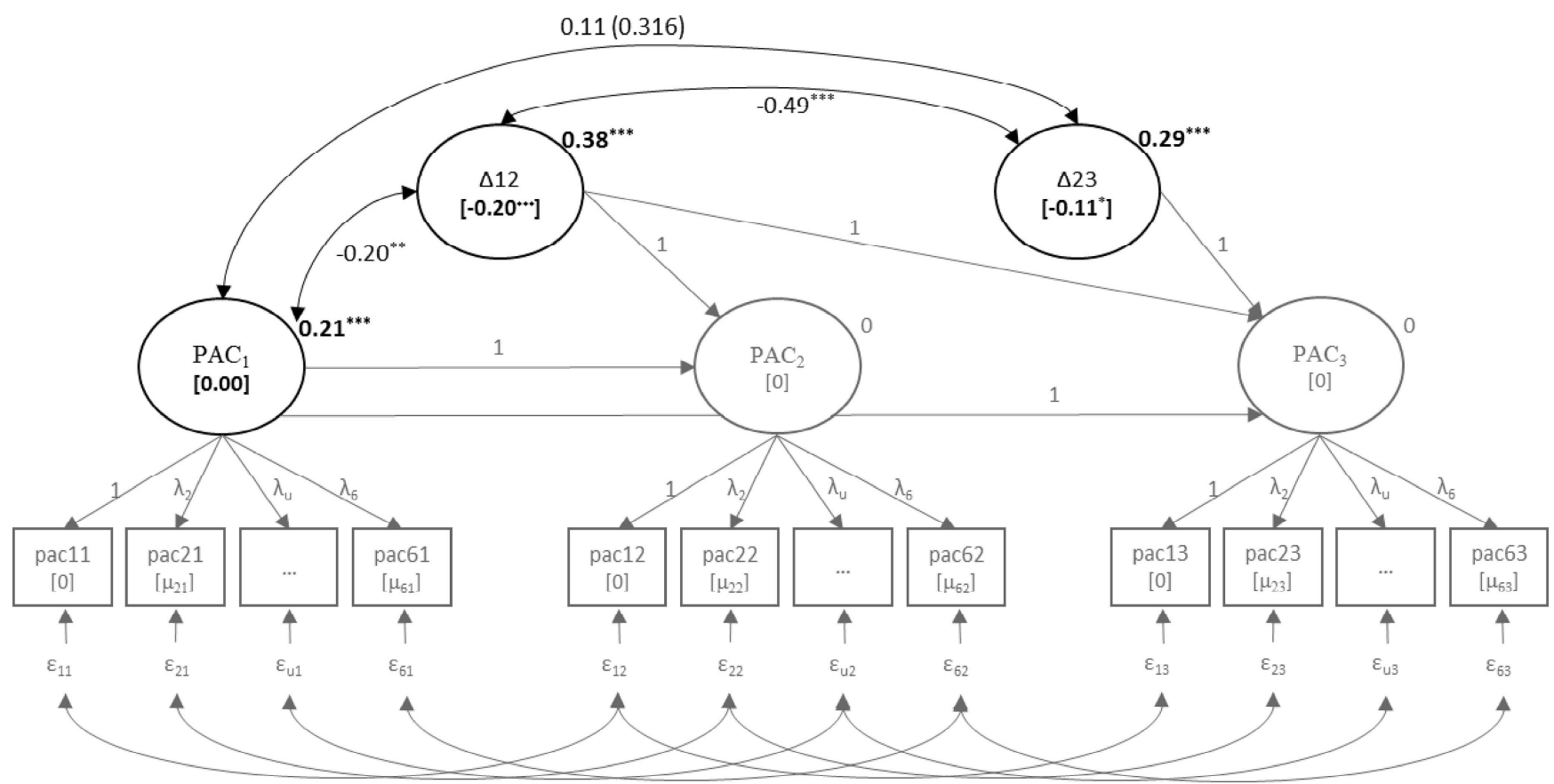

Figure 3. Change in perceived academic control (PAC) over time modeled using a Latent-Change Score model, specifically as a Neighbor-Change model. Maximum likelihood estimation with robust standard errors (MLR). The latent variable PAC had six indicators (pac1-pac6). PAC was measured three times (each academic year). $\mathrm{PAC}_{1}$ is perceived academic control in the first academic year. $\mathrm{PAC}_{2}$ is perceived academic control in the second year. $\mathrm{PAC}_{3}$ is perceived academic control in the third year. $\Delta 12$ is PAC change from the first to second academic year and $\Delta 23$ is PAC change from the second to third academic year. Indicator-specific effects are estimated via autocorrelation. $\chi^{2}(134)=271.51, p<.001$, root mean square error of approximation $($ RMSEA $)=0.03$, comparative fit index $(\mathrm{CFI})=0.94$, standardized root mean square residual $($ SRMR $)=0.07$; $N=1007 .{ }^{*} p<.05 .{ }^{* *} p<.01 .{ }^{* * *} p<.001$. Nonsignificant $p$ values are reported in parentheses.

declined foremost the first academic year. However, high $S D$ s for latent change score intercepts indicated that for some participants, PAC decreased, whereas for others it increased from their beginning to the end of the first academic year (see Table 3).

\section{University Dropout}

To address our second research objective, we conducted an unconditional DTSA to model university dropout. We first tested if the hazard rates for dropout were different across academic years by comparing a DTSA model with no constrained hazard rates against a DTSA model with equally constrained hazard rates (see Table 4). Chi-square difference tests using the log likelihood function (Satorra \& Bentler, 2010) indicated fit was significantly worse in the constrained models $\left(\Delta \chi^{2}(\Delta d f)=64.46(2), p<.001\right)$. Therefore, we proceeded with DTSA models that did not constrain the hazard rates over time. Based on the observed university dropout of our sample, the DTSA estimated an unconditional hazard rate of $14.9 \%$ risk to drop out in the first academic year, of $10.5 \%$ risk to drop out in the second academic year, and of $4.0 \%$ risk to drop out in the third academic year (Table 4, Figure 2). This results in an overall dropout rate of $26.8 \%$ for the entire bachelor degree within this study, which is in line with other relevant assessments at German universities, for instance 33\% for bachelor graduates 2012 (Heublein, 2014). Moreover, we found varying unconditional hazard rates over the three academic years, with the highest probability to drop out of university during the first academic year.

\section{Dropout Focus}

In a second step, we combined the PAC latent change score model with the DTSA dropout model (Figure 4, Table 4). Students with average PAC at the beginning of the first year showed a dropout risk of $14.8 \%$ for the first year. Students with stable PAC within the first year showed a dropout risk of $7.8 \%$ for the second year. Students with a stable PAC within the second year showed a dropout risk of $1.9 \%$ for the third year.

Furthermore, the results of the conditional DTSA model showed only a meaningful impact of PAC changes from the first to second academic year on dropout (see Table 5). The probability of dropping out decreased from 7.8 to $3.1 \%$ for students whose PAC increased by one unit, whereas it increased to $12.5 \%$ for students whose PAC decreased by one unit. Although, the effect of PAC changes from the second to the third academic year on dropout was not significant, it had a meaningful effect size. The probability of dropping out decreased from 1.9 to $0.2 \%$ for students whose PAC increased by one unit, 


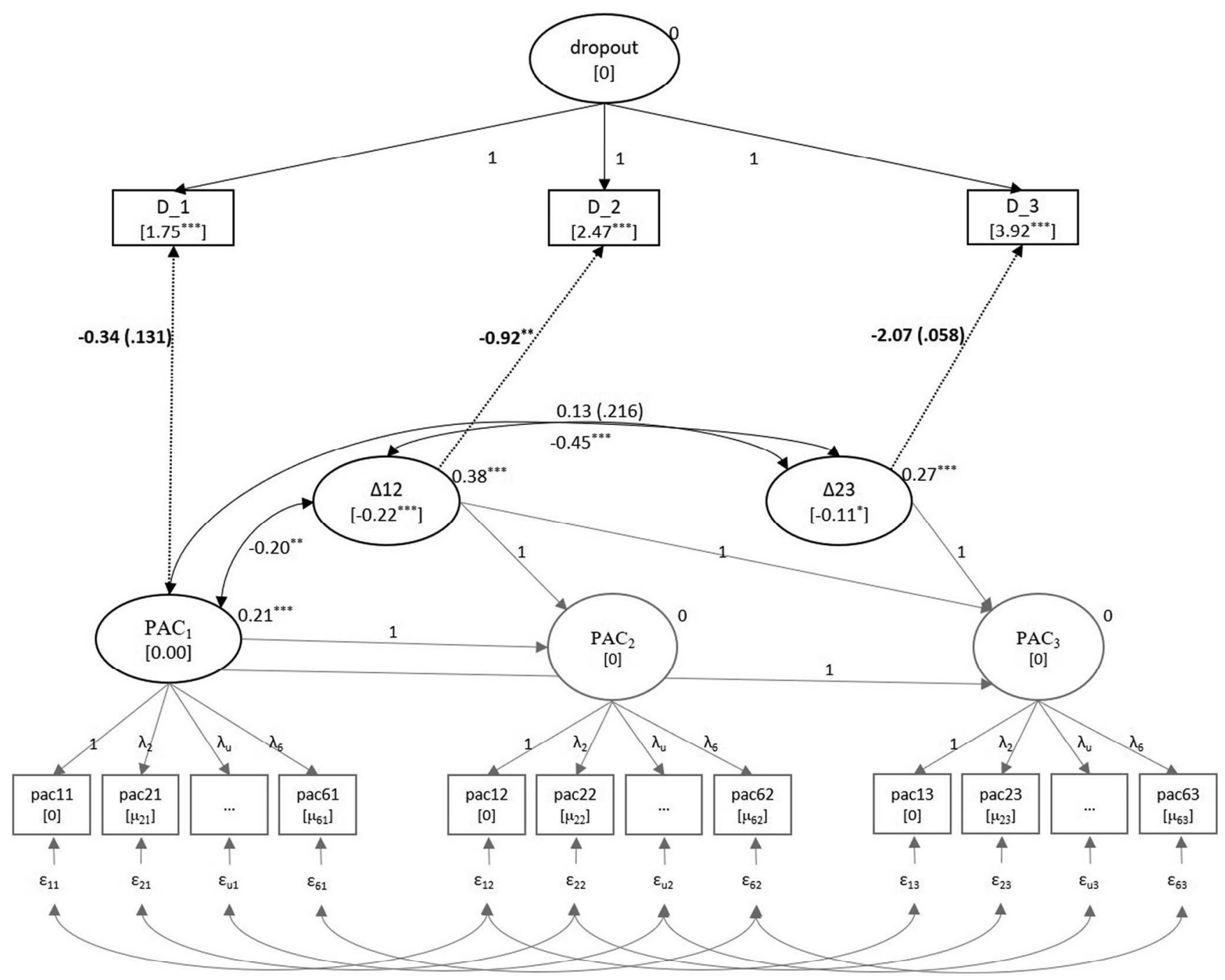

Figure 4. Change in perceived academic control (PAC) over time, modeled using a latent-change model, and its impact on dropout of university, modeled using a discrete time survival model. $\mathrm{PAC}_{1}$ is perceived academic control in the first academic year. $\mathrm{PAC}_{2}$ is perceived academic control in the second year. $\mathrm{PAC}_{3}$ is perceived academic control in the third year. $\Delta 12$ is PAC change from the first to second academic year and $\Delta 23$ is PAC change from the second to third academic year. Maximum likelihood estimation with robust standard errors (MLR). Dropout is operationalized as any kind of university dropout, starting from major change, to university change, to complete dropout. D_1 is dropout in the first year. D_2 is dropout in the second year. D_3 is dropout in the third year. Dropout is the overall dropout within the 3 -year undergraduate program; $N=1,007 .{ }^{*} p<.05$. ${ }^{* *} p<.01 .{ }^{* * *} p<.001$. Nonsignificant $p$ values are reported in parentheses.

whereas it increased to $3.6 \%$ for students whose PAC decreased by one unit.

In summary, the results partially confirmed the assumed positive relation of PAC on university dropout, as an increase in the PAC during the first academic year was related to reduced dropout risk in the second academic year.

\section{Grade Focus}

In a third step, we added GPA to the model (Figure 5, Tables 4 and 5). Consistent with the hypotheses, the model showed PAC positively predicted GPA and vice versa when simultaneously controlling for autoregressive effects. Specifically, high school grades ${ }^{4}$ had a small, but positive impact on PAC at the beginning of the first year. In turn, PAC at the beginning of university positively predicted grades in the first year, which predicted positive change in PAC. Positive changes in PAC over the first academic year had a small, but positive influence on grades within the second academic year. However, second year

${ }^{4}$ The applied proportional DTSA model (Figure 45; AIC $=25824.72$ adj.BIC $=25967.29)$ fit the data better than a nonproportional model $($ AIC $=25826.34$, adj.BIC $=25972.39)$ for the time-invariant impact of high school GPA on dropout. 


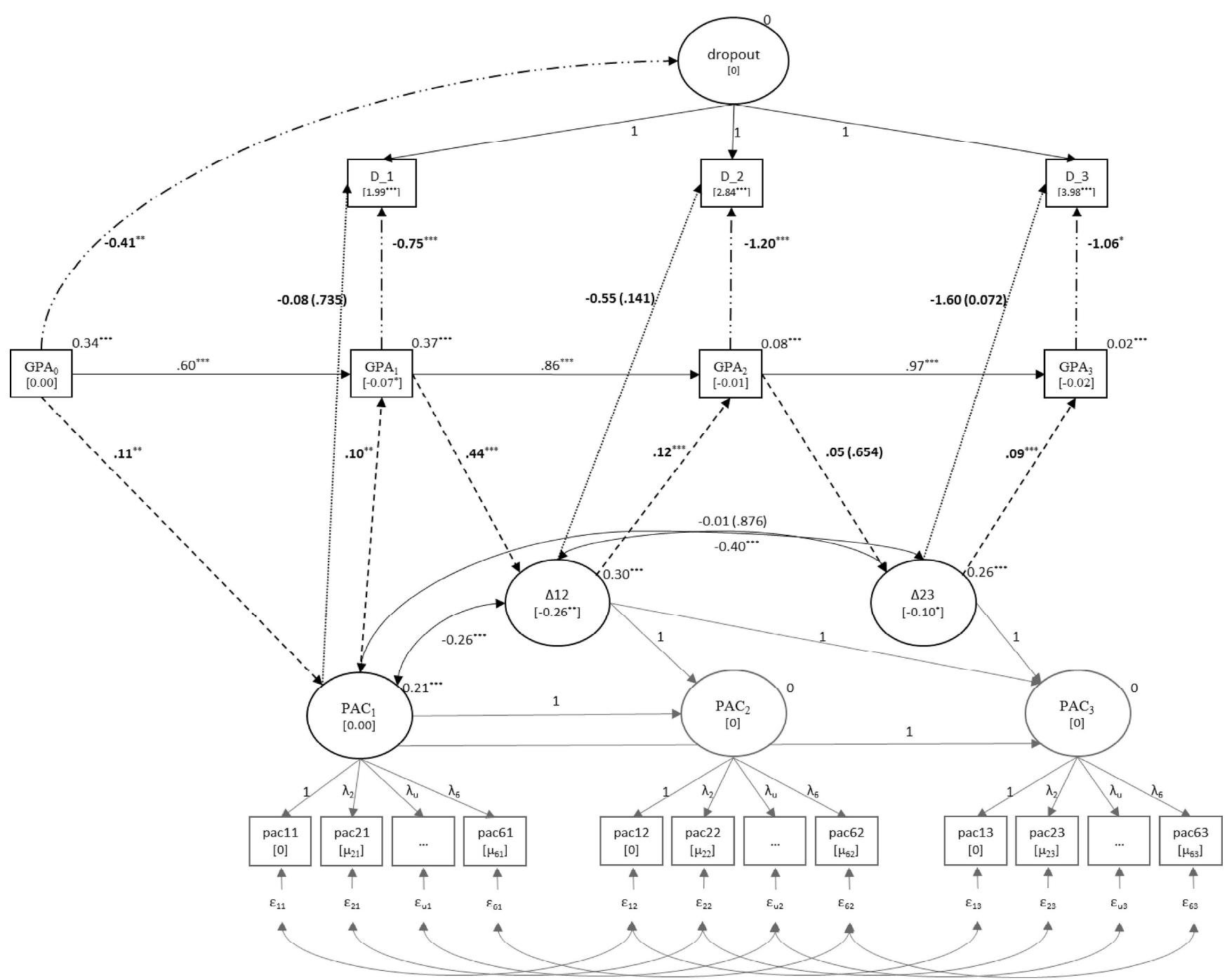

Figure 5. Change in perceived academic control (PAC) over time, modeled using a latent-change model, and its impact on dropout of university as mediated by university grades, modeled using a discrete time survival model. $\mathrm{PAC}_{1}$ is perceived academic control in the first academic year. $\mathrm{PAC}_{2}$ is perceived academic control in the second year. $\mathrm{PAC}_{3}$ is perceived academic control in the third year. $\triangle 12$ is PAC change from the first to second academic year and $\triangle 23$ is PAC change from the second to third academic year. Maximum likelihood estimation with robust standard errors (MLR). University grades are operationalized as cohort-centered grade point average measured in each year (GPA), controlling for high school grades $\left(\mathrm{GPA}_{0}\right) . \mathrm{GPA}_{1}=$ grades midterm first year, $\mathrm{GPA}_{2}=$ grades midterm second year, $\mathrm{GPA}_{3}=$ grades midterm third year. Dropout is operationalized as any kind of university dropout, starting from major change, to university change, to complete dropout. D_1 is dropout in the first year. D_2 is dropout in the second year. D_3 is dropout in the third year. Dropout is the overall dropout within the 3-year undergraduate program; $N=1,007 .{ }^{*} p<.05 .{ }^{* *} p<.01 .{ }^{* * *} p<.001$. Nonsignificant $p$ values are reported in parentheses.

GPA had no meaningful impact on the change of PAC within the second year. Finally, positive change in PAC over the second year had a small, but positive impact on third year grades. In summary, the results provide support for the predicted positive reciprocal longitudinal associations between PAC and GPA when autoregressive effects were controlled.

\section{Mediation Focus}

In the final model, we tested if the association between PAC and dropout was mediated by GPA (Figure 5, Table 5). First, the direct relation of PAC on dropout was no longer significantly different from zero when controlling for subsequent GPA. Second, PAC showed positive reciprocal associations with GPA over time. Third, results showed GPA had strong and negative associations with dropout when controlling for PAC. Therefore, we tested whether GPA mediated the relationship between PAC change and dropout (Fairchild et al., 2015; Voelkle \& Sander, 2008). We found the predicted significant indirect relation of PAC on university dropout. Positive changes in PAC in Year 2 were associated with increased Year 2 grades, which were in turn associated with 
Table 2

Zero-Order Correlations of All Latent Study Variables

\begin{tabular}{|c|c|c|c|c|c|c|c|c|c|c|}
\hline Variable & 1 & 2 & 3 & 4 & 5 & 6 & 7 & 8 & 9 & 10 \\
\hline \multicolumn{11}{|l|}{ PAC } \\
\hline 1. PAC first year & - & & & & & & & & & \\
\hline 2. PAC second year & $.52^{* * *}$ & - & & & & & & & & \\
\hline 3. PAC third year & $.62^{* * *}$ & $.76^{* * *}$ & - & & & & & & & \\
\hline \multicolumn{11}{|l|}{ Dropout of university } \\
\hline 4. Dropout within bachelor study & $-.07(.163)$ & $-.22^{* *}$ & $-.26(.120)$ & - & & & & & & \\
\hline 5. Dropout within first year & $-.08(.132)$ & - & - & - & - & & & & & \\
\hline 6. Dropout within second year & $.01(.934)$ & $-.28^{* *}$ & - & - & - & - & & & & \\
\hline 7. Dropout within third year & $-.11(.323)$ & $.01(.979)$ & $-.30(.113)$ & - & - & - & - & & & \\
\hline \multicolumn{11}{|l|}{ University grades } \\
\hline 8. High school GPA & $.13^{* *}$ & $.23^{* * *}$ & $.40^{* * *}$ & $-.33^{* * *}$ & $-.18^{* * *}$ & $-.24^{* * *}$ & $-.18^{* * *}$ & - & & \\
\hline 9. GPA first year & $.17^{* * * *}$ & $.47^{* * *}$ & $.46^{* * *}$ & $-.34^{* * *}$ & $-.19^{* * *}$ & $-.27^{* * *}$ & $-.14^{* *}$ & $.59^{* * *}$ & - & \\
\hline 10. GPA second year & $.14^{* * * *}$ & $.52^{* * * *}$ & $.52^{* * * *}$ & $-.41^{* * *}$ & - & $-.36^{* * *}$ & $-.14^{* *}$ & $.63^{* * *}$ & $.90^{* * *}$ & - \\
\hline 11. GPA third year & $.14^{* *}$ & $.48^{* * *}$ & $.55^{* * *}$ & $-.30^{* *}$ & - & - & $-.08(.123)$ & $.65^{* * *}$ & $.87^{* * *}$ & $.97^{* * * *}$ \\
\hline
\end{tabular}

Note. $\quad$ PAC $=$ perceived academic control GPA $=$ grade point average. The numbers refer to standardized maximum likelihood parameter estimates with robust standard errors (MLR) for bivariate correlations and point-biserial correlations for dropout. Dropout of university is operationalized as major transfer, university transfer, and complete dropout. University grades are operationalized as cohort-centered grade point average (GPA; high GPA reflects high performance). $N=1007$. Nonsignificant $p$ values are reported in parentheses.

${ }^{* * *} p<.01 .{ }^{* * * *} p<.001$.

reduced odds of Year 2 dropout. ${ }^{5}$ This result confirmed that the influence of $\mathrm{PAC}_{\Delta 12}$ on D_2 was mediated by $\mathrm{GPA}_{2}{ }^{6}{ }^{6}$

Overall, our results showed a dropout risk of $12.1 \%$ for students with average PAC and grades in the first year (see Table 4). This first-year dropout risk was negatively predicted by first-year grades. In detail, the probability of dropping out for students who performed one grade point better than the average was reduced to $5.7 \%$. Vice versa, the probability of dropping out for students who performed one grade point worse than average rose to $18.4 \%$ (see Table 5).

Further, our results showed a dropout risk of $5.5 \%$ for the second year for students with stable PAC within the first year and average grades in the second year. This second year dropout risk was negatively predicted by second-year grades. This means, the probability of dropping out decreased to $1.7 \%$ for students, who performed one grade point better than average in the second year and increased to $9.4 \%$ for students who performed one grade point worse than average. Further, this second year dropout risk was negatively predicted by the mediated relation of PAC change within the first year via GPA in the second year. This means, the initial dropout rate of $5.6 \%$ was reduced to $4.8 \%$ for students whose increases in PAC resulted in better GPA, which in turn

Table 3

Results of the Latent Neighbor-Change Model (See Figure 3)

\begin{tabular}{ccrrrrrr}
$\begin{array}{c}\text { Latent change } \\
\text { score }\end{array}$ & $M$ & $p_{\mathrm{M}}$ & $S E$ & $M 95 \% \mathrm{CI}$ & $S D$ & $p_{S D}$ & $S D 95 \% \mathrm{CI}$ \\
\hline $\mathrm{PAC}_{\Delta 12}$ & -.20 & $<.001$ & .03 & $-.27 /-.14$ & .62 & $<.001$ & $.53 / .70$ \\
$\mathrm{PAC}_{\Delta 23}$ & -.11 & .030 & .05 & $-.21 /-.01$ & .54 & $<.001$ & $.36 / .67$ \\
\hline
\end{tabular}

Note. $\quad \mathrm{CI}=$ confidence interval. $\mathrm{PAC}_{\Delta 12}=$ change of perceived academic control in the first academic year, PAC $_{\Delta 23}=$ changes of perceived academic control in the second academic year, $\chi^{2}(134)=271.51, p<.001$, root mean square error of approximation (RMSEA) $=.03$, comparative fit index $(\mathrm{CFI})=.94$, standardized root mean square residual $(\mathrm{SRMR})=.07$, $N=1,007$. reduced the risk of dropout. The reverse relation led to an increased dropout risk of $6.4 \%$.

Finally, our results showed a dropout risk of $1.8 \%$ for the third year for students with stable PAC within the second year and average grades in the third year. This third year dropout risk was negatively influenced by third-year grades. This means, the probability of dropping out decreased to $0.6 \%$ for students, who performed one grade point better than average in the third year and increased to $3.0 \%$ for students, who performed one grade point worse than average.

In summary, the model explained up to $32 \%$ of the academic year specific dropout variance (see Table 5). These results support the hypothesized relationships between PAC, dropout, and GPA. Additionally, they revealed PACs' impact on dropout and confirmed its expected positive reciprocal longitudinal associations with GPA.

\section{Discussion}

The present study sought to advance the literature on PAC by examining its interrelations and reciprocal longitudinal associa-

\footnotetext{
${ }^{5}$ Additionally, the model estimating both, the direct association of $\mathrm{PAC}_{\triangle 12}$ on D_2 and the indirect association via GPA 2 (Figure 45; AIC = 25824.72 , adj.BIC $=25967.29)$, fit the data worse compared with a mode estimating only the indirect association $(\mathrm{AIC}=25820.67$, adj. $\mathrm{BIC}=$ 25961.50)

${ }^{6}$ We additionally tested alternative specifications for our final model shown in Figure 5. On the one hand, we incorporated paths from prior grades to dropout while still including paths from current grades to dropout (see Table G, Model A of the supplemental materials). None of the additional paths from prior grades were significant because of the high stability of achievement across measurement occasions. On the other hand, we tested an alternative model that incorporated paths from prior grades to dropout while omitting paths from current grades to dropout (see Table $\mathrm{H}$ Model B of the supplemental materials). Results were comparable with those observed in the main analyses. However, both alternative models showed weaker fit than the theoretically preferred model Figure 5, as indicated by higher AIC and BIC values.
} 
Table 4

Overview of Various Dropout DTSA Models (Model Fits and Thresholds)

\begin{tabular}{|c|c|c|c|c|c|c|c|c|c|}
\hline Dropout model & AIC & adj. BIC & $\tau_{D_{-} 1}$ & $\mathrm{~h}(\mathrm{t})_{\mathrm{D} \_1}$ & $\tau_{\mathrm{D} \_2}$ & $\mathrm{~h}(\mathrm{t})_{\mathrm{D} \_2}$ & $\tau_{\mathrm{D} \_3}$ & $\mathrm{~h}(\mathrm{t})_{\mathrm{D} \_3}$ & $R^{2}$ \\
\hline Unconditional, equally constrained & 1747.04 & 1748.78 & 2.16 & $10.3 \%$ & 2.16 & $10.3 \%$ & 2.16 & $10.3 \%$ & \\
\hline Unconditional, not constrained & 1689.19 & 1694.41 & 1.74 & $14.9 \%$ & 2.14 & $10.5 \%$ & 3.17 & $4.0 \%$ & \\
\hline Conditional, not constrained, Figure 4 & 23001.06 & 23107.12 & 1.75 & $14.8 \%$ & 2.47 & $7.8 \%$ & 3.92 & $1.9 \%$ & \\
\hline \multirow[t]{3}{*}{ Conditional, not constrained, Figure 5} & 25824.72 & 25967.29 & 1.99 & $12.1 \%$ & 2.84 & $5.5 \%$ & 3.98 & $1.8 \%$ & $R_{\mathrm{D} \_1}^{2}=.15^{* * *}$ \\
\hline & & & & & & & & & $R_{\mathrm{D}_{2} 2}^{2}=.30^{* * *}$ \\
\hline & & & & & & & & & $R_{\mathrm{D} \_3}^{2}=.32^{* *}$ \\
\hline
\end{tabular}

Note. $\quad \mathrm{AIC}=$ Akaike information criterion; ${ }_{\text {adj }} \mathrm{BIC}=$ sample-size adjusted Bayesian information criterion; $\tau=$ threshold; $\mathrm{h}(\mathrm{t})=\mathrm{hazard}$ rate $=1 /(1+$ $\left.\mathrm{e}^{\tau}\right) \triangleq$ dropout risk; D_1 = dropout in first year; D_2 = dropout in second year; D_3 = dropout in third year. $N=1,007$. All Discrete Time Survival Analysis (DTSA) were computed with the MLR estimator (maximum likelihood estimation with robust standard errors) using expectation maximization (EM) algorithm optimization method and the numerical integration algorithm with 5,000 random integration points.

${ }^{* *} p<.01 .^{* * *} p<.001$.

tions involving university dropout and university grades over 3 years of an academic program. Study results showed that (a) most students experienced decreased levels of PAC in their first year (change focus), (b) changes in PAC predicted university dropout (dropout focus), (c) positive reciprocal longitudinal associations operated between positive PAC changes and university grades (grade focus), and (d) the associations between PAC change and dropout were mediated by university grades (mediation focus).

\section{Change Focus-PAC of University Students}

The observed negative changes in PAC within the first year were in line with the existing literature (Niculescu et al., 2016; Respondek et al., 2017; Stupnisky et al., 2012). PAC decreased to a much greater extent in the first year relative to the second year, which extends previous research (e.g., Hall, 2008; Perry et al., 2001). This suggests the initial transition to university has negative implications for changes in students' PAC (cf. e.g., Perry, 1991, 2003; Perry et al., 2001; Perry, Hladkyj, et al., 2005).

An explanation for the relatively strong decrease in first-year PAC could be that the baseline measurement was before any performance feedback. As stated by the Attribution Theory of Motivation and Emotion (Weiner, 1985) and shown by Hall (2008), students may be prone to changes in perceived control after failure. This could imply a correction process while adjusting to university, whereby students enter university with inflated levels of PAC that change (decrease) to better reflect reality over time. Freshman students may be unaware of how much control they actually have, because of the novel and unfamiliar learning environment. Students may have initially overestimated their academic control (cf. e.g., Ruthig et al., 2007; Ruthig, Perry, Hall, \& Hladkyj, 2004) and subsequently adjusted it after receiving their first performance feedback at university.

Table 5

Overview of Various Dropout DTSA Models (Parameter Estimates of Predictors and Corresponding Odds Ratios)

\begin{tabular}{|c|c|c|c|c|c|c|c|}
\hline Model & Parameter estimates & $\beta$ & $p_{\beta}$ & $\beta 95 \% \mathrm{CI}$ & OR & OR $95 \% \mathrm{CI}$ & $\%_{\mathrm{OR}}$ \\
\hline \multirow[t]{3}{*}{ Figure 4} & $\mathrm{PAC}_{1}-\mathrm{D} \_1$ & -.34 & .131 & {$[-.78, .10]$} & .71 & {$[.46,1.11]$} & $28.8 \%$ \\
\hline & $\mathrm{PAC}_{\Delta 12}-\mathrm{D} \_2$ & -.92 & .006 & {$[-1.57,-.27]$} & .40 & {$[.21, .76]$} & $60.1 \%$ \\
\hline & $\mathrm{PAC}_{423}-\mathrm{D}_{-} 3$ & -2.07 & .058 & {$[-4.21, .07]$} & .13 & {$[.02,1.07]$} & $87.4 \%$ \\
\hline \multirow[t]{15}{*}{ Figure 5} & $\mathrm{PAC}_{1}-\mathrm{D}_{-} 1$ & -.08 & .735 & {$[-.54, .40]$} & .92 & {$[.58,1.47]$} & $7.7 \%$ \\
\hline & $\mathrm{PAC}_{\Delta 12}-\mathrm{D} \_2$ & -.55 & .141 & {$[-1.26, .20]$} & .58 & {$[.28,1.20]$} & $42.3 \%$ \\
\hline & $\mathrm{PAC}_{\Delta 23}-\mathrm{D} \_3$ & -1.60 & .072 & {$[-3.30, .10]$} & .20 & {$[.04,1.16]$} & $79.8 \%$ \\
\hline & $\mathrm{GPA}_{0}$ - Dropout & -.41 & .011 & {$[-.71,-.07]$} & .66 & {$[.48, .91]$} & $33.6 \%$ \\
\hline & $\mathrm{GPA}_{1}$ - D_1 & -.75 & $<.001$ & {$[-1.12,-.40]$} & .47 & {$[.33, .68]$} & $52.8 \%$ \\
\hline & $\mathrm{GPA}_{2}-\mathrm{D} \_2$ & -1.20 & $<.001$ & {$[-1.97,-.50]$} & .30 & {$[.14, .63]$} & $69.9 \%$ \\
\hline & $\mathrm{GPA}_{3}-\mathrm{D}_{-} 3$ & -1.06 & .021 & {$[-1.98,-.16]$} & .35 & {$[.14, .85]$} & $65.4 \%$ \\
\hline & $\mathrm{GPA}_{0}-\mathrm{PAC}_{1}$ & .11 & .003 & {$[.03, .16]$} & - & - & - \\
\hline & $\mathrm{PAC}_{1}-\mathrm{GPA}_{1}$ & .10 & .004 & {$[.03, .16]$} & - & - & - \\
\hline & $\mathrm{GPA}_{1}-\mathrm{PAC}_{\triangle 12}$ & .44 & $<.001$ & {$[.35, .54]$} & - & - & - \\
\hline & 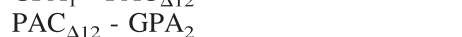 & .12 & $<.001$ & {$[.06, .17]$} & - & - & - \\
\hline & $\mathrm{GPA}_{2}-\mathrm{PAC}_{\Delta 23}$ & .05 & .654 & {$[-.17, .29]$} & - & - & - \\
\hline & $\mathrm{PAC}_{\Delta 23}-\mathrm{GPA}_{3}$ & .09 & .001 & {$[.04, .15]$} & - & - & - \\
\hline & $\mathrm{PAC}_{\Delta 12}-\mathrm{GPA}_{2}-\mathrm{D} \_2\left(\right.$ mediation $\left.\mathrm{ab}_{2}\right)$ & -.16 & .012 & {$[-.29,-.04]$} & .85 & {$[.75, .96]$} & $14.8 \%$ \\
\hline & 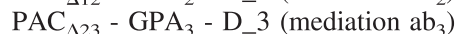 & -0.13 & .096 & {$[-0.29,0.02]$} & .88 & {$[.75,1.00]$} & $12.2 \%$ \\
\hline
\end{tabular}

Note. $\quad \mathrm{CI}=$ confidence interval; $O R=$ odds ratio $=\mathrm{e}^{\beta} ; \%_{\mathrm{OR}}=$ amount of change in dropout probability for each one unit change in the predictor variable $=((1-O R) \times 100), N=1,007$. All Discrete Time Survival Analysis (DTSA) were computed with the MLR estimator (maximum likelihood estimation with robust standard errors) using expectation maximization (EM) algorithm optimization method and the numerical integration algorithm with 5000 random integration points. 
On the other hand, students experienced on average small negative changes within the second academic year and PAC showed strong autocorrelations over the three academic years. Those results indicate a relative stability after students adjusted to university (cf. Ruthig et al., 2009), which is in line with assumptions about the disposition-like nature of PAC (Perry, Hall, et al., 2005).

However, high variance of the overall decrease indicated that for some students the decrease was even greater, or for others there was no change or even an increase. This variability indicated all three possibilities of change (declines, stability, and increases), which underscores the relevance of multiple PAC assessments over time.

\section{Dropout Focus-PAC and University Dropout}

After we analyzed the change in PAC over an entire undergraduate program of study, we focused on its relevance for university dropout and university grades, and tested whether university grades mediated the relation of PAC on university dropout.

Our study participants showed in general an expected overall dropout rate of nearly one third (cf. Heublein, 2014). Contrary to Voelkle and Sander (2008), we found university dropout to be different for each undergraduate year, with the highest dropout for the first academic year (cf. Alarcon \& Edwards, 2013; Heublein et al., 2017). These findings support prior research that focuses on the first-year experience being especially important. Nevertheless, about half of the overall dropout occurred after the first academic year. This late dropout (Mabel \& Britton, 2018; Willcoxson et al., 2011) points to the importance of the present study's examination of an entire academic program.

By following students over several years, we found that for students with average baseline control perceptions that remained stable over time the dropout risk was already lower than the overall average dropout risk. This finding highlights the academic risks that accompany low PAC and extends previous research by showing the impact of levels and changes in PAC on university dropout beyond dropout intention or voluntary course withdrawal (e.g., Hall et al., 2006; Perry, Hladkyj, et al., 2005; Respondek et al., 2017).

In detail, it seems as if initial changes in PAC that accompany the adaption to university are mostly relevant for dropout (as opposed to baseline PAC perceptions). These findings differ somewhat from those observed by Perry, Hladkyj, et al. (2005), who found PAC to be relevant for students' departures especially in the third year. One explanation of that diverse relevance for dropout could be that the present study obtained baseline control perception data before students' first performance feedback and, therefore, before the occurrence of a potential correction process as mentioned earlier (Weiner, 1985). Another explanation could be that overly optimistic expectations during this transition period could reflect an academic risk factor, as the adjustment to university can consist of frequent failure experiences that may contradict the initially high PAC perceptions of some students (Ruthig et al., 2004). Finally, the impact of the positive PAC changes in Year 2 showed, however, close to meaningful associations with reduced dropout risk in the subsequent year. Nonsignificant associations could be a consequence of various reasons (e.g., reduced thirdyear dropout rates or third-year sample size). In summary, PAC changes were shown to have important implications for university dropout, especially in Year 2, which expands on prior research examining course withdrawals (e.g., Hall et al., 2006; Ruthig et al., 2007) or dropout intentions (e.g., Respondek et al., 2017).

\section{Grade Focus-PAC and University Grades}

This study is the first to examine the interplay of PAC and performance over an entire undergraduate program of study, thereby extending prior research (Perry et al., 2001; Perry, Hladkyj, et al., 2005). Our results showed prior university grades to strongly predict subsequent university grades at each time point (cf., Geiser \& Santelices, 2007; Richardson et al., 2012; Schneider \& Preckel, 2017). However, PAC still exhibited significant positive relationships with university grades. The study, therefore, highlights the relevance of high and increasing levels of PAC for students over an entire academic program of study, broadening previous work (Stupnisky et al., 2007, 2012).

The study findings highlight positive reciprocal longitudinal associations between PAC change and university grades. In other words, students' high school grades predicted higher PAC at the beginning of their studies, which enhanced their grades within the first year, which produced a strong increase in PAC, and that subsequently enhanced their second-year grades. Besides the nonsignificant effect of the second-year grades on second-year PAC change, the study provides strong support for the hypothesized positive reciprocal longitudinal associations.

One explanation why the positive reciprocal longitudinal associations occurred mainly in the first year could be the importance of the causal search after failure experiences (Weiner, 1985, 2018). In our study, the first performance feedback was highly relevant for changes in students' control perceptions. As students adjust to university, their control perceptions may become more accurate via performance feedback, resulting in positive reciprocal longitudinal associations especially in the first year. Later on in the study, PAC became more stable, resulting in weaker positive reciprocal longitudinal associations.

Further, the relationship between the first-year baseline PAC and university grades was lower than expected from prior research (e.g., Perry et al., 2001; Perry, Hladkyj, et al., 2005). One explanation could be the prior mentioned students' overestimation of PAC at the beginning of the first year, especially since they had yet to receive performance feedback. Thus, the study points to the potential role of veridicality or accuracy of high PAC. Presumably, PAC is adjusted to better reflect reality after the first performance feedback. These subsequent perceptions of control that may be more accurate may better predict university grades later on.

However, baseline PAC perceptions that may have been overestimated still had a weak positive effect on first-year university grades. Further, high levels of baseline PAC and subsequent positive changes in PAC appear to be adaptive for future university grades, even if those perceptions are inaccurate. This implies that, even if their perceptions are becoming more accurate, it is maladaptive that most students experienced declines in PAC. 


\section{Mediation Focus-Interrelationships Between PAC, University Dropout, and University Grades}

Finally the present study sought to advance the literature by focusing on whether university grades mediated the association between PAC and university dropout. The data supported our hypothesis and showed that university grades accounted for PAC relations on second-year dropout risk. In general, university grades were a very strong predictor for dropout (cf. e.g., Voelkle \& Sander, 2008). However, PAC still remained relevant, with its indirect relation via university grades underscoring its influence. This suggests a low PAC level does not 'only' have negative consequences for university grades, but also indirectly leads to university dropout. Therefore, our results point to PAC as an important psychosocial predictor of university success. To enhance retention and performance, students require high levels of initial PAC and/or increasing PAC levels, especially in the first academic year. Then again, PAC represents one facet of expectancy of success. Thus, referring to expectancy value models (for an overview see, e.g., Eccles \& Wigfield, 2002) students' perceived value and the interaction of expectancy and value should also be considered as predictor of university success (e.g., for secondary school settings, see Trautwein et al., 2012). However, within the higher education setting of the present study, value is presumably relatively high with limited heterogeneity between the students (e.g., Dresel \& Grassinger, 2013), which is in contrast to PAC.

Overall, the results support the assumptions in the psychological model of college student retention (Bean \& Eaton, 2001) that proposes PAC as a key predictor of freshman dropout, as it influences university grades that later affects dropout. Moreover, our results indirectly support the Attributional Theory of Achievement Motivation and Emotion (Weiner, 1985, 2018) concerning the interrelationship between (negative) achievement outcomes as an initiator of causal search. Finally, the study extends prior research on the relation of PAC on dropout (e.g., Perry, Hladkyj, et al., 2005) and university grades (e.g., Perry et al., 2001) by simultaneously analyzing longitudinal PAC effects on both key elements of university success.

\section{Limitations and Implications for Future Research}

We used a latent change score model to address our first research objective regarding how annually assessed PAC changes over three undergraduate years. Future research should broaden our results by measuring control perceptions at more frequent time intervals using latent growth models to test assumptions about the functional form of the change. Moreover, future research should consider heterogeneity by examining the three patterns of decreasing, stable, and increasing control perception, as we found high variability in students' PAC changes (cf. e.g., Niculescu et al., 2016; Voelkle \& Sander, 2008). Additionally, we sought to extend prior research through multiple measurements of PAC within an entire undergraduate program of study. As mentioned before, our first year measurement occurred before any performance feedback and may have influenced our results. To better understand the influence of level and change in perceived control, this early measurement was important. However, future research should examine whether our 3-year findings are consistent when baseline measures of self-reported PAC occur after early achievement tests, such as mock exams, partial tests, or scored exercises (Perry \& Hamm, 2017).

We used discrete time survival analysis models to address our second research objective that focused on how PAC is relevant for university success. We modeled the actual undergraduate dropout accounting for the specific time when dropout occurred. However, we used a broad operationalization of dropout (Bernardo et al. 2017) and had no information about the reasons for student dropout (cf. Alarcon \& Edwards, 2013). Future research should address this issue by conducting follow-up sessions with students who withdrew.

In our final estimated DTSA model, we did not account for all possible effects, such as the possible effect of first year grades on second or even third year dropout (see Figure 5). In this study, we wanted to estimate the most parsimonious models that would adequately test our complex research objectives. Future research could test those alternative models that account for all possible paths. However, testing such complex models would probably require even more participants or cohorts (cf. Little, 2013).

We focused on PAC and found about a third variance of university dropout was explained by PAC and university grades. Yet, other factors could also influence dropout. For instance, Heublein et al. (2017) surveyed German university dropout and described the following main motives: educational demands that were too high, lack of motivation, and lack of practical tasks at university. These were followed by financial reasons and personal reasons such as sickness. Additionally, dropout can possibly result from an intentional decision that the study program does not fit personal expectations and needs, for instance because of lack of information (Aymans \& Kauffeld, 2015). Another important predictor of university success is value. As described previously, the interaction of expectancy and value may be relevant in predicting achievement (e.g., Trautwein et al., 2012). Therefore, it seems reasonable that an interaction of value and PAC should influence university dropout over time and future research should additionally consider academic value. Therefore, future studies should consider more factors that may simultaneously influence university dropout.

This field study was conducted within the university environment to ensure high ecological validity. Because of this design expected levels of attrition were observed, especially by the third year (Moerbeek, 2014). Our design also enabled us to confirm that university grades mediated the association between PAC and dropout risk. Future research should consider additional possible mediators, such as the students' achievement emotions (Respondek et al., 2017; Ruthig et al., 2008). For instance, Pekrun and colleagues (2017) found positive developmental feedback loops between emotions and achievement. As posited by Pekrun (2006), PAC may serve as an antecedent of emotions in a PAC-emotionachievement sequence. As the current study highlighted the relevance of not only level of PAC but also change in first-year PAC for university dropout and grades, it supports the reciprocal assumption of the control-value theory (Pekrun, 2006) and even broadens it by pointing to the relevance of change in first-year PAC. Therefore, future research on the control-value theory (Pekrun, 2006) may benefit from a more in depth examination of the role of changes in PAC.

We used the common operationalization of university grades: grade point average, which is not a fixed metric. Future research should include an actual performance test with a metric that is 
stable over time and, thus, permits the measurement of students' actual gains in achievement. However, we note that such a measure would need to be subject-specific.

Finally, specific methods of instruction could have implications for PAC levels, depending on the learning environment. For example, some instructors or methods of instruction may support students' PAC more than others (cf. Implications for Educational Practice). Future studies should focus on the effects of learning environments (e.g., because of various majors, programs, instructors, etc.) and systematically assess different aspects of the instruction, perhaps starting with a few specific study majors for more homogeneity. It would be interesting to understand how different methods of instruction affect students' perceptions of control.

\section{Implications for Educational Practice}

This study points to the relevance of PAC for university success, especially for freshman students. However, this study revealed an overall negative trend of students' control perceptions, especially in the first year. Therefore, it is relevant for institutions and instructors to consider supporting strategies to enhance retention and performance. Students' PAC can be supported, either directly via established Attributional Retraining or indirectly via instructional design (Clifton, Hamm, \& Parker, 2015). Our results also show that PAC changes after performance feedback, which may reflect an optimal time to support it. This implies that first year experience enhancing programs should not start too early from an attributional perspective. Similarly, Attributional Retraining treatments that are typically administered after initial performance feedback have been shown to enhance students' PAC and even their general sense of control (Perry, Hall, et al., 2005; Perry \& Hamm, 2017). Instructors can also support students' control perception through increasing predictability and controllability for students, for instance, via well-structured courses, timely and constructive failure feedback, and clearly articulated task expectations (cf. Perry, Hall, et al., 2005; Stupnisky et al., 2007). Additionally, early identification of students' level of academic control may help to assists especially low-control students who are 'at risk' of dropout (Haynes, Perry, Stupnisky, \& Daniels, 2009; Perry, Hladkyj, et al., 2005).

To improve retention and university grades, the present study suggests that institutions and instructors should provide early supports to help maintain and enhance students' perceptions of control over their academic outcomes. Nevertheless, the present longitudinal study also points to the relevance of monitoring students' perceived control over the entire program of study. Results highlight the development of PAC throughout university and reveal its importance beyond the first year experience by showing that it predicts subsequent university dropout and university grades. Taken together, our study suggests the need for institutional programs designed to enhance students' perceptions of control to foster their long-term university success.

\section{References}

Alarcon, G. M., \& Edwards, J. M. (2013). Ability and motivation: Assessing individual factors that contribute to university retention. Journal of Educational Psychology, 105, 129-137. http://dx.doi.org/10.1037/ a0028496
Allen, J., Robbins, S. B., Casillas, A., \& Oh, I.-S. (2008). Third-year college retention and transfer: Effects of academic performance, motivation, and social connectedness. Research in Higher Education, 49, 647-664. http://dx.doi.org/10.1007/s11162-008-9098-3

Aymans, S. C., \& Kauffeld, S. (2015). To leave or not to leave? Critical factors for university dropout among first-generation students. Zeitschrift Für Hochschulentwicklung, 10, 23-43. http://dx.doi.org/10 .3217/zfhe-10-04/02

Bahr, P. R. (2009). Educational attainment as process: Using hierarchical discrete-time event history analysis to model rate of progress. Research in Higher Education, 50, 691-714. http://dx.doi.org/10.1007/s11162009-9135-X

Bean, J. P., \& Eaton, S. B. (2001). The psychology underlying successful retention practices. Journal of College Student Retention: Research, Theory and Practice, 3, 73-89. http://dx.doi.org/10.2190/6R55-4B3028XG-L8U0

Bernardo, A., Cervero, A., Esteban, M., Tuero, E., Casanova, J. R., \& Almeida, L. S. (2017). Freshmen program withdrawal: Types and recommendations. Frontiers in Psychology, 8, 1544. http://dx.doi.org/10 .3389/fpsyg.2017.01544

Cassidy, S., \& Eachus, P. (2000). Learning style, academic belief systems, self-report student proficiency and academic achievement in higher education. Educational Psychology, 20, 307-322. http://dx.doi.org/10 $.1080 / 713663740$

Christ, O., \& Schlüter, E. (2012). Strukturgleichungsmodelle mit Mplus. Eine praktische Einführung [Structural equation modeling with Mplus. A practical introduction]. München: Oldenbourg. http://dx.doi.org/10 $1524 / 9783486714807$

Clifton, R. A., Hamm, J. M., \& Parker, P. C. (2015). Promoting effective teaching and learning in higher education. In M. B. Paulsen (Ed.), Higher education: Handbook of theory and research (Vol. 30, pp. 245-274). Cham: Springer International Publishing.

Credé, M., \& Niehorster, S. (2012). Adjustment to college as measured by the student adaptation to college questionnaire: A quantitative review of its structure and relationships with correlates and consequences. Educational Psychology Review, 24, 133-165. http://dx.doi.org/10.1007/ s10648-011-9184-5

Daniels, L. M., Perry, R. P., Stupnisky, R. H., Stewart, T. L., Newall N. E. G., \& Clifton, R. A. (2014). The longitudinal effects of achievement goals and perceived control on university student achievement. European Journal of Psychology of Education, 29, 175-194. http://dx .doi.org/10.1007/s10212-013-0193-2

DesJardins, S. L., Ahlburg, D. A., \& McCall, B. P. (1999). An event history model of student departure. Economics of Education Review, 18, 375-390. http://dx.doi.org/10.1016/S0272-7757(98)00049-1

Dresel, M., \& Grassinger, R. (2013). Changes in achievement motivation among university freshmen. Journal of Education and Training Studies, 1, 159-173. http://dx.doi.org/10.11114/jets.v1i2.147

Eccles, J. S., \& Wigfield, A. (2002). Motivational beliefs, values, and goals. Annual Review of Psychology, 53, 109-132. http://dx.doi.org/10 .1146/annurev.psych.53.100901.135153

Enders, C. K. (2010). Applied missing data analysis. Methodology in the social sciences. New York, NY: Guilford Press.

Faas, C., Benson, M. J., Kaestle, C. E., \& Savla, J. (2018). Socioeconomic success and mental health profiles of young adults who drop out of college. Journal of Youth Studies, 21, 669-686. http://dx.doi.org/10 $.1080 / 13676261.2017 .1406598$

Fairchild, A. J., Abara, W. E., Gottschall, A. C., Tein, J.-Y., \& Prinz, R. J. (2015). Improving our ability to evaluate underlying mechanisms of behavioral onset and other event occurrence outcomes: A discrete-time survival mediation model. Evaluation \& the Health Professions, 38, 315-342. http://dx.doi.org/10.1177/0163278713512124

Geiser, C. (2011). Datenanalyse mit Mplus: Eine anwendungsorientierte Einführung [Data analysis with Mplus: A application-oriented introduc- 
tion]. Wiesbaden: VS-Verl. http://dx.doi.org/10.1007/978-3-53193192-0

Geiser, S., \& Santelices, M. V. (2007). Validity of high-school grades in predicting student success beyond the freshman year: High-school record vs. standardized tests as indicators of four-year college outcomes. Center for Studies in Higher Education Research \& Occasional Paper Series. (CSHE 6.07).

Gottschall, A. C., Fairchild, A. J., Masyn, K. E., \& Prinz, R. J. (2013, May). An empirical illustration of discrete-time survival mediation analysis: A new tool to assess the how and when of event occurrence. Poster presented at the Society for Prevention Research 21st Annual Meeting 2013, San Francisco, CA.

Hair, J. F., Black, W. C., Babin, B. J., \& Anderson, R. E. (Eds.). (2010). Multivariate data analysis: A global perspective (7th ed.). Upper Saddle River, NJ: Pearson.

Hall, N. C. (2008). Self-regulation of primary and secondary control in achievement settings: A process model. Journal of Social and Clinical Psychology, 27, 1126-1164. http://dx.doi.org/10.1521/jscp.2008.27.10 .1126

Hall, N. C., Perry, R. P., Ruthig, J. C., Hladkyj, S., \& Chipperfield, J. G. (2006). Primary and secondary control in achievement settings: A longitudinal field study of academic motivation, emotions, and performance. Journal of Applied Social Psychology, 36, 1430-1470. http://dx .doi.org/10.1111/j.0021-9029.2006.00067.x

Hamm, J. M., Perry, R. P., Chipperfield, J. G., Murayama, K., \& Weiner, B. (2017). Attribution-based motivation treatment efficacy in an online learning environment for students who differ in cognitive elaboration. Motivation and Emotion, 41, 600-616. http://dx.doi.org/10.1007/ s11031-017-9632-8

Hamm, J. M., Perry, R. P., Chipperfield, J. G., Parker, P. C., \& Heckhausen, J. (2019). A motivation treatment to enhance goal engagement in online learning environments: Assisting failure-prone college students with low optimism. Motivation Science, 5, 116-134. http://dx.doi.org/ 10.1037/mot0000107

Haynes, T. L., Perry, R. P., Stupnisky, R. H., \& Daniels, L. M. (2009). A review of attributional retraining treatments: Fostering engagement and persistence in vulnerable college students. In J. C. Smart (Ed.), Higher education: Handbook of theory and research (Vol. 24, pp. 227-272). Dordrecht, the Netherlands: Springer. http://dx.doi.org/10.1007/978-14020-9628-0_6

Heckhausen, J., \& Schulz, R. (1995). A life-span theory of control. Psychological Review, 102, 284-304. http://dx.doi.org/10.1037/0033-295X .102.2.284

Heublein, U. (2014). Student drop-out from German higher education institutions. European Journal of Education, 49, 497-513. http://dx.doi .org/10.1111/ejed.12097

Heublein, U., Ebert, J., Hutzsch, C., Isleib, S., König, R., Richter, J., \& Woisch, A. (2017). Zwischen Studienerwartungen und Studienwirklichkeit: Ursachen des Studienabbruchs, beruflicher Verbleib der Studienabbrecherinnen und Studienabbrecher und Entwicklung der Studienabbruchquote an deutschen Hochschulen [Between expectations and reality: Reasons for university dropout, occupational whereabouts, and development of dropout rates in Germany]. Forum Hochschule, 2017. Retrieved from https://www.dzhw.eu/pdf/pub_fh/fh-201701.pdf

Heublein, U., \& Wolter, A. (2011). Studienabbruch in Deutschland. Definition, Häufigkeit, Ursachen, Maßnahmen [University dropout in Germany. Definition, frequency, reasons, provisions]. Zeitschrift fur Padagogik, 57, 214-236.

Hu, L.-T., \& Bentler, P. M. (1999). Cutoff criteria for fit indexes in covariance structure analysis: Conventional criteria versus new alternatives. Structural Equation Modeling, 6, 1-55. http://dx.doi.org/10.1080/ 10705519909540118

Little, T. D. (2013). Longitudinal structural equation modeling. New York, NY: Guilford Press.
Mabel, Z., \& Britton, T. A. (2018). Leaving late: Understanding the extent and predictors of college late departure. Social Science Research, 69, 34-51. http://dx.doi.org/10.1016/j.ssresearch.2017.10.001

Masyn, K. E. (2003). Discrete-time survival mixture analysis for single and recurrent events using latent variables (Doctoral dissertation). Retrieved from http://www.statmodel.com/download/masyndissertation.pdf

Masyn, K. E. (2014). Discrete-time survival analysis in prevention science. In Z. Sloboda \& H. Petras (Eds.), Advances in prevention science. Defining prevention science (pp. 513-535). Boston, MA: Springer. http://dx.doi.org/10.1007/978-1-4899-7424-2_22

McArdle, J. J. (2001). A latent difference score approach to longitudinal dynamic structural analysis. In R. Cudek, D. Sörbom, S. Du Toit, \& K. Jöreskog (Eds.), Structural equation modeling: Present and future (pp. 341-380). Lincolnwood, IL: Scientific software international.

Moerbeek, M. (2014). Sufficient sample sizes for discrete-time survival analysis mixture models. Structural Equation Modeling, 21, 63-67. http://dx.doi.org/10.1080/10705511.2014.856697

Muthén, B. O., \& Masyn, K. E. (2005). Discrete-time survival mixture analysis. Journal of Educational and Behavioral Statistics, 30, 27-58. http://dx.doi.org/10.3102/10769986030001027

Muthén, L. K., \& Muthén, B. O. (2017). Mplus user's guide (8th ed.). Los Angeles, CA: Author. (Original work published 1998)

Niculescu, A. C., Tempelaar, D. T., Dailey-Hebert, A., Segers, M., \& Gijselaers, W. H. (2016). Extending the change-change model of achievement emotions: The inclusion of negative learning emotions. Learning and Individual Differences, 47, 289-297. http://dx.doi.org/10 .1016/j.lindif.2015.12.015

OECD. (2012). Education today 2013: The OECD perspective. Advance online publication. http://dx.doi.org/10.1787/edu_today-2013-en

Pascarella, E. T., \& Terenzini, P. T. (2005). How college affects students: A third decade of research (Vol. 2). San Francisco, CA: Jossey-Bass.

Pekrun, R. (2006). The control-value theory of achievement emotions: Assumptions, corollaries, and implications for educational research and practice. Educational Psychology Review, 18, 315-341. http://dx.doi .org/10.1007/s10648-006-9029-9

Pekrun, R. P., Goetz, T., Perry, R. P., Kramer, K., Hochstadt, M., \& Molfenter, S. (2004). Beyond test anxiety: Development and validation of the Test Emotions Questionnaire (TEQ). Anxiety, Stress, \& Coping, 17, 287-316. http://dx.doi.org/10.1080/10615800412331303847

Pekrun, R., Lichtenfeld, S., Marsh, H. W., Murayama, K., \& Goetz, T. (2017). Achievement emotions and academic performance: Longitudinal models of reciprocal effects. Child Development, 88, 1653-1670. http:// dx.doi.org/10.1111/cdev.12704

Perry, R. P. (1991). Perceived control in college students: Implications for instruction in higher education. Higher Education: Handbook of Theory and Research, 7, 1-56.

Perry, R. P. (2003). Perceived (academic) control and causal thinking in achievement settings. Canadian Psychology, 44, 312-331. http://dx.doi .org/10.1037/h0086956

Perry, R. P., Hall, N. C., \& Ruthig, J. C. (2005). Perceived (academic) control and scholastic attainment in higher education. In J. C. Smart (Ed.), Higher education: Handbook of theory and research (Vol. 20, pp. 363-436). Dordrecht, the Netherlands: Springer. http://dx.doi.org/10 .1007/1-4020-3279-X_7

Perry, R. P., \& Hamm, J. M. (2017). An attribution perspective on competence and motivation: Theory and treatment interventions. In A. J. Elliot, C. S. Dweck, \& D. S. Yeager (Eds.), Handbook of competence and motivation: Theory and application (pp. 61-84). New York, NY: Guilford Press.

Perry, R. P., Hladkyj, S., Pekrun, R. P., Clifton, R. A., \& Chipperfield, J. G. (2005). Perceived academic control and failure in college students: A three-year study of scholastic attainment. Research in Higher Education, 46, 535-569. http://dx.doi.org/10.1007/s11162-005-3364-4 
Perry, R. P., Hladkyj, S., Pekrun, R. P., \& Pelletier, S. T. (2001). Academic control and action control in the achievement of college students: A longitudinal field study. Journal of Educational Psychology, 93, 776789. http://dx.doi.org/10.1037/0022-0663.93.4.776

Respondek, L., Seufert, T., Stupnisky, R., \& Nett, U. E. (2017). Perceived academic control and academic emotions predict undergraduate university student success: Examining effects on dropout intention and achievement. Frontiers in Psychology, 8, 243. http://dx.doi.org/10.3389/ fpsyg.2017.00243

Richardson, M., Abraham, C., \& Bond, R. (2012). Psychological correlates of university students' academic performance: A systematic review and meta-analysis. Psychological Bulletin, 138, 353-387. http://dx.doi.org/ 10.1037/a0026838

Robbins, S. B., Lauver, K., Le, H., Davis, D., Langley, R., \& Carlstrom, A. (2004). Do psychosocial and study skill factors predict college outcomes? A meta-analysis. Psychological Bulletin, 130, 261-288. http:// dx.doi.org/10.1037/0033-2909.130.2.261

Robbins, S. B., Oh, I.-S., Le, H., \& Button, C. (2009). Intervention effects on college performance and retention as mediated by motivational, emotional, and social control factors: Integrated meta-analytic path analyses. Journal of Applied Psychology, 94, 1163-1184. http://dx.doi .org/10.1037/a0015738

Ruthig, J. C., Hanson, B. L., \& Marino, J. M. (2009). A three-phase examination of academic comparative optimism and perceived academic control. Learning and Individual Differences, 19, 435-439. http://dx.doi .org/10.1016/j.lindif.2009.03.004

Ruthig, J. C., Haynes, T. L., Perry, R. P., \& Chipperfield, J. G. (2007). Academic optimistic bias: Implications for college student performance and well-being. Social Psychology of Education, 10, 115-137. http://dx .doi.org/10.1007/s11218-006-9002-y

Ruthig, J. C., Perry, R. P., Hall, N. C., \& Hladkyj, S. (2004). Optimism and attributional retraining: Longitudinal effects on academic achievement, test anxiety, and voluntary course withdrawal in college students. Journal of Applied Social Psychology, 34, 709-730. http://dx.doi.org/10 .1111/j.1559-1816.2004.tb02566.x

Ruthig, J. C., Perry, R. P., Hladkyj, S., Hall, N. C., Pekrun, R. P., \& Chipperfield, J. G. (2008). Perceived control and emotions: Interactive effects on performance in achievement settings. Social Psychology of Education, 11, 161-180. http://dx.doi.org/10.1007/s11218-007-9040-0

Satorra, A., \& Bentler, P. M. (2010). Ensuring positiveness of the scaled difference chi-square test statistic. Psychometrika, 75, 243-248. http:// dx.doi.org/10.1007/s11336-009-9135-y

Schneider, M., \& Preckel, F. (2017). Variables associated with achievement in higher education: A systematic review of meta-analyses. Psychological Bulletin, 143, 565-600. http://dx.doi.org/10.1037/ bul0000098

Skinner, E. A. (1996). A guide to constructs of control. Journal of Personality and Social Psychology, 71, 549-570. http://dx.doi.org/10.1037/ 0022-3514.71.3.549
Stevens, J. (2009). Applied multivariate statistics for the social sciences (5th ed.). New York, NY: Routledge.

Stewart, S., Lim, D. H., \& Kim, J. (2015). Factors influencing college persistence for first-time students. Journal of Developmental Education, $38,12-20$

Steyer, R., Eid, M., \& Schwenkmezger, P. (1997). Modeling true intraindividual change: True change as a latent variable. Methods of Psychological Research, 2, 21-33.

Steyer, R., Partchev, I., \& Shanahan, M. J. (2000). Modeling true intraindividual change in structural equation models: The case of poverty and children's psychosocial adjustment. In T. Little, K. U. Schnabel, \& J. Baumert (Eds.), Modeling longitudinal and multilevel data: Practical issues, applied approaches, and specific examples (pp. 95-111). Mahwah, NJ: Erlbaum.

Stupnisky, R. H., Perry, R. P., Hall, N. C., \& Guay, F. (2012). Examining perceived control level and instability as predictors of first-year college students' academic achievement. Contemporary Educational Psychology, 37, 81-90. http://dx.doi.org/10.1016/j.cedpsych.2012.01.001

Stupnisky, R. H., Renaud, R. D., Perry, R. P., Ruthig, J. C., Haynes, T. L. \& Clifton, R. A. (2007). Comparing self-esteem and perceived control as predictors of first-year college students' academic achievement. Social Psychology of Education, 10, 303-330. http://dx.doi.org/10.1007/ s11218-007-9020-4

Trautwein, U., Marsh, H. W., Nagengast, B., Lüdtke, O., Nagy, G., \& Jonkmann, K. (2012). Probing for the multiplicative term in modern expectancy-value theory: A latent interaction modeling study. Journal of Educational Psychology, 104, 763-777. http://dx.doi.org/10.1037/ a0027470

Voelkle, M. C., \& Sander, N. (2008). University dropout: A structural equation approach to discrete-time survival analysis. Journal of Individ ual Differences, 29, 134-147. http://dx.doi.org/10.1027/1614-0001.29.3 .134

Weiner, B. (1985). An attributional theory of achievement motivation and emotion. Psychological Review, 92, 548-573. http://dx.doi.org/10.1037/ 0033-295X.92.4.548

Weiner, B. (2018). The legacy of an attribution approach to motivation and emotion: A no-crisis zone. Motivation Science, 4, 4-14. http://dx.doi .org/10.1037/mot0000082

Willcoxson, L., Cotter, J., \& Joy, S. (2011). Beyond the first-year experience: The impact on attrition of student experiences throughout undergraduate degree studies in six diverse universities. Studies in Higher Education, 36, 331-352. http://dx.doi.org/10.1080/03075070903581533 